REVIEW

\title{
Helper T cells and atherosclerosis: the cytokine web
}

\author{
S G Baidya, Q-T Zeng
}

Postgrad Med J 2005;81:746-752. doi: 10.1136/pgmj.2004.029827

There is growing evidence regarding the importance of inflammation in the pathogenesis of atherosclerosis and its ultimate progression to the clinical syndromes.

Recently there has been an increasing interest in the role of helper T (Th) cells in atherosclerosis. The Th cells act with the macrophages and the dendritic cells via the various cytokines in bringing about a variety of changes thus leading to the progression of atherosclerosis. Atherosclerotic lesions have been seen to have increased expression of type 1 helper T (TH1) cells together with increased levels of the Th1 related cytokines. It is mainly the cytokines involved with Th1 functioning that seem to show a prominent effect, with the whole process centred around interferon gamma, making it seem like every pathway and the cytokines involved lead to a final common pathway of interferon gamma secretion; the increase or decrease of which dictates the progression of atherosclerosis and its final manifestation as the clinical syndromes.

See end of article for authors' affiliations

Correspondence to

Correspondence to:
Dr Q-T Zeng, Department of Interventional Cardiology, Institute of Cardiovascular Diseases, Union Hospital, Tongii Medical College, Huazhong University of Science and Technology, 1277 Jie-Fang Avenue, Wuhan, 430022, Hubei Province, PR China; qt_zeng@hotmail.com

Submitted 17 October 2004 Accepted 6 March 2005
$\mathrm{T}$ he multifactorial causation of chronic diseases makes them a challenge for therapeutic interventions and atherosclerosis is no exception. Atherosclerosis as a process is today known to begin even during fetal development especially in fetuses of hypercholesterolaemic mothers. ${ }_{-}^{1}$ With both the genetic and environmental factors acting in concert, the disease process can have severe consequences. The world of science has come up with a whole list of factors regarded as risk factors for the start and the progression of atherosclerosis ending up in its clinical manifestations. Within the past few years there has been growing evidence regarding the importance of inflammatory mechanisms in the pathogenesis of atherosclerosis and its ultimate progression to atherosclerosis related diseases, particularly coronary artery diseases (CAD). Fatty streak, the earliest manifestation of atherosclerosis is an inflammatory lesion consisting of macrophages and $\mathrm{T}$ lymphocytes. ${ }^{2}$ Studies further suggested a role for CD4+ helper $\mathrm{T}$ (Th) cells in atherosclerosis. ${ }^{3}{ }^{4}$ These Th cells are important regulators of the immune system, and when activated secrete multiple cytokines that modulate the immune response and control the secretion of cytokines from other cells, like the macrophages. Evidence further shows that among the CD4+ T cells it is the T helper 1 (Thl) subtype that seems to be dominant in atherosclerosis. $^{5}$
In this review we discuss ways in which the Th cells, in particular the type 1 subset of Th cells, interact in the process of atherogenesis and the web of cytokines involved around the functioning of these cells in the regulation of the immune response in atherosclerosis.

\section{IMMUNOLOGICAL BACKGROUND: T HELPER CELLS AND THEIR SUPPORTERS}

The immune response of the body to an antigen is a complicated process with the involvement of multiple cells and a whole range of adhesion molecules and cytokines. Antigen presenting cells (APCs), like the dendritic cells (DCs) and macrophages, process antigens and present them to specific immune system cells through major histocompatibility complex (MHC) expression on the cells surface. T cells are activated only if they could recognise the antigens presented by the APCs through MHC. The APCs also produce cytokines that help in their interaction with the $\mathrm{T}$ cells. Activation of $\mathrm{T}$ cells, in particular the Th cells, cause the production and release of cytokines and further leads to the activation of Th cells themselves to proliferate and differentiate into effector cells playing a part in the development of cellular or humoral immune responses.

Th cells have an important role in the regulation of the immune response. Th cells develop in the thymus gland together with cytotoxic T cells. T cells bearing the CD4 molecule as their specific surface antigens become Th cells. Those bearing the CD8 molecules become cytotoxic T cells. T cells in the immature stage when not exposed to antigens are known as naive $\mathrm{T}$ cells. These naive $\mathrm{T}$ cells recognise antigens presented by the APCs such as the DCs, macrophages, and the B cells. These APCs phagocytose antigens, process them, and then present them with the MHC class II molecule. Th cells then recognise the antigens in the context of MHC class II molecules. Th cells are classified functionally into Thl and Th2 subtypes on the basis of difference in cytokine production. ${ }^{6}$ The Thl subset shows specific production of interferon gamma, interleukin (IL) 2, and tumour necrosis factor (TNF) $\alpha$ and plays a greater part in the cellular immunity. Th2 cells, which mainly

Abbreviations: Th, T helper; IFN, interferon; $C A D$, coronary artery disease; DC, dendritic cell; APC, antigen presenting cell; $M H C$, major histocompatibility complex; IL, interleukin; TLR, toll-like recptor; SMC, smooth muscle cell; LPL, lipoprotein lipase; LDL, low density lipoprotein; oxLDL, oxidised low density lipoprotein; ACAT, acyl coenzyme A cholesterol acyl-transferase; CRP, C reactive protein; HSP, heat shock protein; ECM, extracellular matrix; TNF, tumour necrosis factor 
produce IL4, IL5, and IL10, on the other hand promote humoral immunity.

Two other important cell types and their cytokines are closely interwoven with Th cell functioning; the antigen presenting DCs and monocyte derived macrophages. DCs are potent regulators of the immune system that show their functional activity by processing and presenting antigens to other cells, mainly T cells. DC precursors (blood monocytes) undergo transendothelial migration and phagocytosis and with the help of coactivators like GM-CSF and IL4 form DCs. Distinct subsets of DCs are involved in the differential regulation of the Th1/Th2 balance. ${ }^{7}$ Type 1 DCs (DC1) originate from DCl precursors. These myeloid-like DCl stimulate Thl cells, with expression of CD154 ( CD40L). This gives an outlet for the cell mediated immune response. Lymphoid-like type 2 DCs (DC2) arise from DC2 precursors. It is the Th2 cells that are stimulated by the DC2, which further help B cells to produce antibodies. Macrophages are an essential part of the immune defences in a host and they act as the most important agents for host defences in primitive organisms. With evolution there has been a shift in importance from innate to adaptive immune response with the $\mathrm{T}$ lymphocytes taking increasing control of the immune system. Nevertheless, macrophages still are important players in the immune response, acting in concert with the other agents, especially $\mathrm{T}$ lymphocytes, by producing various cytokines. The relation can be to such an extent that the macrophages have been seen to show varied responses (Ml or M2 type responses) that might be able to differentially influence Th1/Th2 or other types of immune responses. ${ }^{8}$ Apart from the other functions of macrophages it is the formation of foam cells in the atherosclerotic lesions that makes them a prominent cell type in atherosclerosis.

\section{IMPORTANCE OF THE INNATE IMMUNE SYSTEM}

Although the adaptive immune system forms a more specialised form of defence mechanism, the response to an antigen leading to clonal expansion of the lymphocytes takes at least a few days to result in the generation of effector cells. It is becoming more evident that the innate immune system, which acts through antimicrobial peptides, phagocytes, and the alternative pathway, has a much more important role than was thought before. In contrast with the adaptive immune system, the innate immune system starts its effector functions immediately after coming in contact with the antigens.

Innate immune system mainly acts via recognition of a range of molecular patterns (bacterial lipopolysaccharides, peptidoglycans, lipotechoic acids, bacterial DNA, double stranded RNA, and the mannans) associated with the pathogens. The receptors in the innate immune system that recognise such molecular patterns are known as "pattern recognition receptors". Such receptors are mainly present on the professional antigen presenting cells such as macrophages and DCs. A group of such receptors, the endocytic pattern recognition receptors, are found on the surface of macrophages and promote the attachment of microorganisms to phagocytes leading to their subsequent engulfment and destruction. The resulting peptides are then presented with the MHC on the surface of the macrophages. In recent years another group of receptors belonging to the toll family have been seen to play important parts in immune responses. Toll-like receptors (TLRs) are named for the homologues of the toll receptors in drosophilia. ${ }^{9}$ TLRs induce the activation of NFKB pathway that further leads to the expression of a range of cytokines and costimulatory molecules important for the activation of the adaptive immune system, mainly to drive the naive Th cells towards the IFN gamma producing Thl subtype. ${ }^{10}$ Activated $\mathrm{NF \kappa B}$ has been detected in the different cells in atherosclerotic lesions ${ }^{11}$ and experimental studies have shown the role of $\mathrm{TLRs}^{12}$ and $\mathrm{NF \kappa B}^{13}$ in atherosclerosis, thus supporting the concept of the innate immune system also taking part in the immune mechanisms involved in atherogenesis.

\section{MAJOR INTERLEUKINS INVOLVED WITH THE T HELPER CELL RESPONSE}

A whole range of identified cytokines have been shown to play a part in atherogenesis, some with pro-atherogenic properties while others having antiatherogenic properties. Here we will discuss in brief only a few cytokines, the interleukins related to the Th cell response in atherosclerosis.

IL2, mainly secreted by Thl cells, is an autocrine stimulator of Thl cell differentiation and proliferation ${ }^{14}$ resulting in a $\mathrm{T}$ cell shift towards Thl phenotype. It was found to be expressed in atheroma ${ }^{5}$ and suggested to have a proatherogenic effect in experimental models. ${ }^{15}$ The serum concentrations of IL2 were found to be increased in patients of ischaemic heart diseases further suggesting its role in atherosclerosis related diseases. ${ }^{16}$

IL4, a Th2 cell interleukin, is considered to be potentially pro-inflammatory and pro-atherogenic while having some antiatherogenic effects as well. It thus shows pleiotropic effects giving rise to a complex function. Some examples of the pro-atherogenic effects are up regulation of p-selectin, ${ }^{17}$ 15-lipoxygenase, ${ }^{18}$ and VCAM-1. ${ }^{19}$ The antiatherogenic actions are the inhibition of smooth muscle cells proliferation $^{20}$ and inhibition of macrophage adhesiveness. ${ }^{21}$ Uyemura et al however showed the expression of IL4 in atherosclerotic plaques to be limited, casting doubts over the pro-atherogenic roles in vivo. ${ }^{22}$

IL10 is a prototype anti-inflammatory interleukin produced mainly by activated T cells, B cells, and macrophages. It was described in mice as a Th2 cytokine that selectively inhibited IFN gamma and GM-CSF production by the Thl cells, ${ }^{23}$ while in humans IL10 was seen to affect the cytokine production from both Thl and Th2 cells. ${ }^{24}$ IL10 also has been seen to down regulate the pro-inflammatory roles of macrophages. ${ }^{25}$ A potential modulatory role for IL10 in the progression of atherosclerosis was seen in murine models, ${ }^{26}$ and a possible protective role of IL10 against atherosclerosis was further seen. ${ }^{27}$ Significantly low concentrations of IL10 have been seen in patients with CAD. ${ }^{28} 29$

IL12 is a proinflammatory interleukin mainly produced by the macrophages, B cells, and DCs. It promotes Thl cells functioning while causing suppression of Th2 cells functions. Apo-E deficient mice when given with IL12 showed progression of atherosclerosis with a change in the levels of oxidised LDL suggesting a pro-atherogenic role for IL12. ${ }^{30}$ IL12 further acts in synergy with IL18 for the production of IFN gamma by the T cells. ${ }^{31}{ }^{32}$ Furthermore, cross regulatory roles for IL12 and IL10 have been shown suggesting antagonising action of each to the biological effects of the other. ${ }^{22}$ Increased serum concentrations of IL12 have been seen in patients with CAD. ${ }^{29}$

IL18, earlier also known as the IFN gamma inducing factor, is another pro-inflammatory interleukin with multiple biological functions. It is mainly produced by macrophages. IL18 by its actions on T cells, specifically the Thl subtype, induces IFN gamma production. ${ }^{33}{ }^{34}$ IL1 8 has further been seen to induce production of IFN gamma by the macrophages as well as the human vascular smooth muscle cells. ${ }^{35}$ It has been seen to be expressed in atherosclerotic plaques ${ }^{36}$ and studies suggest a pro-atherogenic role for it. ${ }^{35-37}$ The serum concentrations of IL18 are increased in patients of acute coronary syndromes and seem to correlate with the severity of myocardial dysfunction. ${ }^{38}$ 


\section{T HELPER TYPE 1 CELL DOMINANCE IN ATHEROSCLEROSIS}

Most of the $\mathrm{T}$ lymphocytes present in the atherosclerotic plaques both in humans ${ }^{3}$ as well as in animal models ${ }^{4}$ were seen to be CD4+ T cells. These CD4 bearing Th cells have a central regulatory role in immune and autoimmune responses and are further classified mainly into Thl subtype and Th2 subtype according to the cytokines they secrete. Studies in experimental models show a pro-atherogenic role for Thl cells and an antiatherogenic role for Th2 cells. ${ }^{39}{ }^{40} \mathrm{Th}$ cells present in the atherosclerotic lesions showed properties of Th 1 phenotype with increased levels of IFN gamma and IL2 whereas the Th2 cytokines IL4, IL5, and IL10 were found in only modest quantities. ${ }^{5}$ The cells in the lesion also produce the Thl stimulatory cytokines ILl2 $2^{22}$ and IL18. ${ }^{34} 35$ Both DCs and activated macrophages by means of the IL12 they produce interact with the Thl cells leading to the production of IFN gamma and IL2. IL12 further acts in synergy with IL18 mainly produced by the activated macrophages, resulting in production of IFN gamma and thus cause a shift towards Thl type cytokine production. ${ }^{31}{ }^{32}$ The Th2 cytokines IL4 and especially IL10 are mainly of antiinflammatory nature both of which can act to inhibit the production of IFN gamma by Thl cells. IL10 and IL12 have cross regulatory roles whereby IL10 inhibits the functions of Th1 cells and IL12 inhibits Th2 cell functions. ${ }^{22}$ IL4 and IL10 were only detected in a minority of the atherosclerotic plaques studied compared with the finding of IFN gamma in all the atherosclerotic lesions suggesting the suppressed activity of Th2 cells. ${ }^{22}$ All these findings together with the increased levels of Thl related cytokines such as IL12, IL18, and IFN gamma seen in patients of CAD and the decreased levels of Th2 related cytokine IL10 seen in the same groups as discussed earlier point towards a dominant role of Thl cell activity in atherosclerosis and its progression. Figure 1 summarises the web of cytokines involved in Th cell response leading to progression of atherosclerosis.

\section{IFN GAMMA AND ATHEROSCLEROSIS}

There seems to be a complex interwoven relation between a multitude of cytokines arising from DCs, macrophages, and Th cells that includes both the type 1 as well as the type 2 cells (fig 1). Centred within this complex web seems to be IFN gamma, secreted mainly by Thl cells as well as by macrophages and smooth muscle cells (SMCs). ${ }^{33-35}$

Cytokines like IL12 and IL18 secreted by macrophages and DCs mainly in combination induce the production of IFN gamma. IFN gamma in turn activates macrophages, which produce proinflammatory cytokines, oxygen radicals, and metalloproteinases. IFN gamma directly inhibits Th2 cells proliferation and creates a positive feedback loop by up regulating the production of IL12 receptors. ${ }^{41}$ In recent years IFN gamma has been postulated to have a significant role in atherogenesis as well as its complications. Proliferation of the vascular SMC is one of the hallmarks of atherosclerosis and IFN gamma has been seen to be important regulator of SMC proliferation. $^{42}$ IFN gamma has been reported to increase vascular cell adhesion molecule- 1 on endothelial cells ${ }^{43}$ and MHC class II antigens on macrophages and smooth muscle cells $^{44} 45$ thus implicating its role in the immune response. One of the most important effects of IFN gamma in atherosclerosis is related to cholesterol metabolism and foam cells formation. IFN gamma may play a part by affecting lipid accumulation in atherosclerotic lesion by inhibiting macrophage lipoprotein lipase (LPL) at least in part via a reduction of LPL synthesis. ${ }^{46}$ The enzyme cholesterol 27-hydroxylase, which promotes the removal of cholesterol from the arterial walls and acts as a defence against atherosclerosis, has been seen to be down-regulated by IFN gamma. ${ }^{47}$ IFN gamma further inhibits cholesterol efflux in the macrophages mediated by down-regulation of ATP binding cassette transporter $\mathrm{l}(\mathrm{ABCl})^{48}$ and the stimulation of acyl coenzyme A: cholesterol acyl-transferase (ACAT), ${ }^{49}$ shifting the balance towards lipid accumulation and formation of foam cells, ultimately thus the progression of atherosclerosis. A further role of IFN gamma in the formation of foam cells was seen through its ability to up regulate the CXCL16/SR-PSOX. ${ }^{50} 51$ CXCL16 is a recently discovered chemokine of the CXC family that shows an identical sequence to SR-PSOX, a scavenger receptor for phosphatidylserine and oxidised LDL (SR-PSOX), seen to be expressed in atherosclerotic lesions that mediate internalisation of oxidised low density lipoproteins (oxLDL) and phosphatidylserine coated particles such as apoptotic bodies. ${ }^{52} \mathrm{~A}$ direct relation between IFN gamma

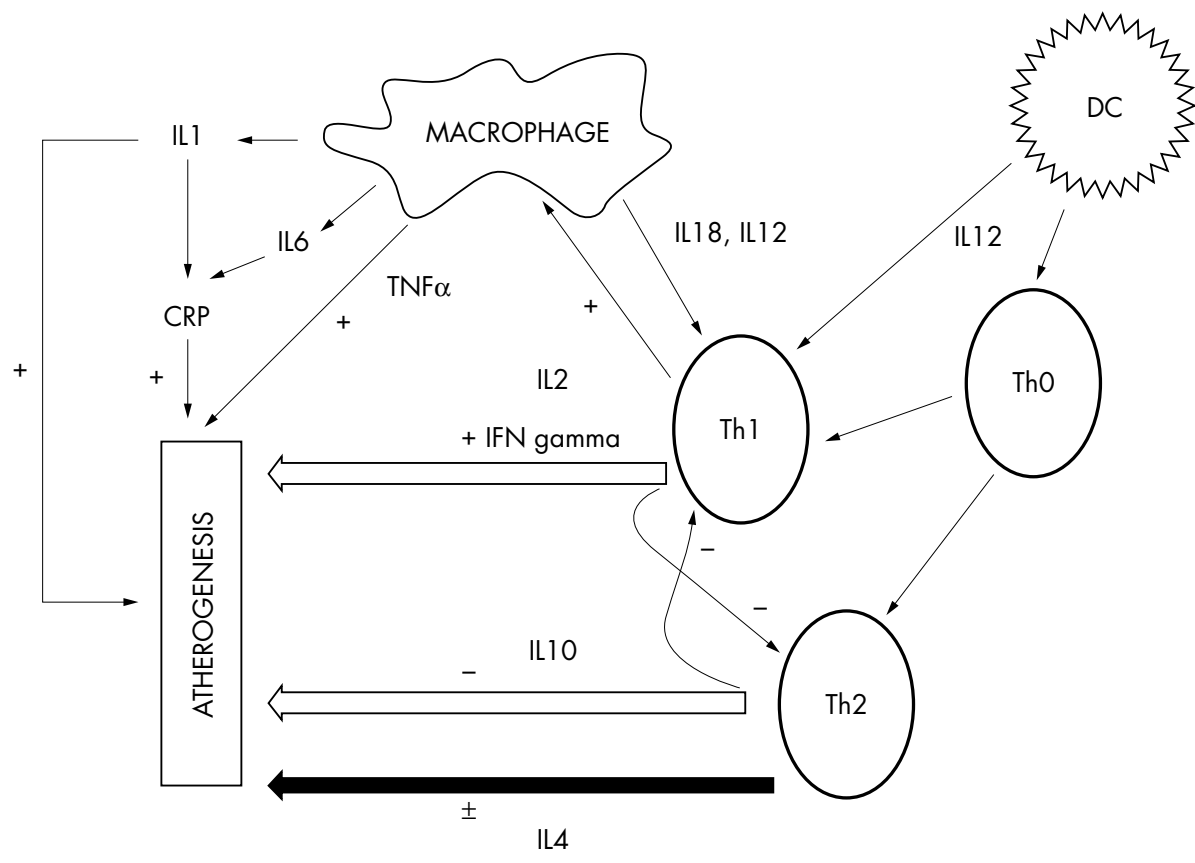

Figure 1 Schematic diagram showing the major cytokines, their source, and their effects in the process of atherogenesis. IL12 and IL1 8 from DCs and macrophages result in Th cell differentiation into Th1 phenotype as well as cause stimulation of the Th1 cells. Thl cells in turn by producing IFN gamma activate macrophages. ILI and IL6 produced by the macrophages result in the production of CRP and all of them together result in pro-atherogenic effects. IL2 and especially IFN gamma from Thl cells, also, by various mechanisms, act to increase atherogenesis while IL10 from Th2 cells act as an antiartherogenic cytokine. The effects of IL4 are pleiotrophic having pro-atherogenic as well as antiartherogenic actions. CRP, C reactive protein; DC dendritic cell; IL, interleukin; IFN, interferon; Th, T helper cell; TNF, tumour necrosis factor. 
and atherosclerosis has been shown in animal models where enhancement of the disease process in apolipoprotein E-/mice occurred on administration of IFN gamma. ${ }^{53}$

An atherosclerotic plaque becomes vulnerable when the fibrous cap gets thinned out with a large lipid core, decrease in the SMC content, and extensive inflammatory cells (mainly macrophges) accumulation occurs within the plaque together with endothelial denudation or dysfunction. ${ }^{54}$ IFN gamma can lead to the plaques being vulnerable via its effects on extracellular matrix synthesis. ${ }^{55}$ Furthermore, it is a potent regulator of cathepsin S, a serine protease, expressed in vascular smooth muscle cells, ${ }^{45}$ and cathepsin $S$ has been seen to play a part in the breakdown of extracellular matrix in atherosclerosis. ${ }^{56}$ Possible effects of IFN gamma in the induction of inducible Ca2+/calmodulin independent NOS $(\text { iNOS })^{57}$ further suggests its role in endothelial dysfunction. Plaque instability, regarded as a gateway to the consequences of atherosclerosis, has an important contribution from the accelerated apoptosis of the macrophages. ${ }^{58}$ IFN gamma has also been seen to induce the apoptosis of THPl macrophages. ${ }^{59}$ The possible proatherogenic effects of IFN gamma discussed in this review are summarised in the box.

\section{THE OTHER CYTKINES IN LINE AND CRP}

One important multifunctional cytokine worth mentioning is $\mathrm{TNF} \alpha$, which is mainly produced by the macrophages although also seen to be produced by the Thl cells. This cytokine, which is one of the most potent proinflammatory cytokines, has also been suggested to have a role in atherosclerosis and its progression. ${ }^{60}$ The Thl cells together with the action of IFN gamma on the macrophages causes

Possible effects of IFN gamma in promoting atherosclerosis

Effects on lipid accumulation and foam cell formation

- inhibition of LPL

- down-regulation of cholesterol 27-hydroxylase

- down-regulation of $A B C 1$

- stimulation of ACAT

- up-regulation of the CXCL16/SR-PSOX

Effects on cellular structure in the plaque

- SMC proliferation

- macrophage activation

- induce apoptosis of macrophages

- autocrine stimulation of Th 1 cells

- inhibition of Th2 cells proliferation

- increased expression of MHC class II molecules on macrophages and SMC.

\section{Other effects}

- increase expression of adhesion molecules(VCAM-1)

- activation of iNOS to increase NO synthesis

- decrease the ECM content

$A B C-1$, ATP binding cassette transporter 1; $A C A T$, acyl coenzyme A cholesterol acyl-transferase; CXCL, CXC chemokine ligand; ECM, extracellular matrix; iNOS, inducible $\mathrm{Ca} 2+/$ calmodulin independent nitric oxide synthase; LPL, lipoprotein lipase; SMC, smooth muscle cell; SR-PSOX, scavenger receptor for phosphatidylserine and oxidised LDL; VCAM, vascular cell adhesion molecule. secretion of ILl. ILl in itself is a key mediator of inflammation. Increased ILl concentrations have been seen in human atherosclerotic plaques. ${ }^{61}$ It promotes the inflammatory response in atherosclerosis through a range of effects. $^{62}$ ILl can also cause the release of IL6, a secondary proinflammatory cytokine, from the SMCs. ${ }^{63}$ IL6 is also secreted by other cells like lymphocytes and macrophages ${ }^{64}$ and is an IL found in atherosclerotic plaques. ${ }^{65}$ It has an important role in the stimulation of CRP synthesis by the liver. ${ }^{66}$ CRP has also been seen to be synthesised locally within the atherosclerotic plaques. ${ }^{67}$ Previously believed just to be an innocent by product of immune activation in atherogenesis, it is now known to have a role in stimulatory effects on many cells in the plaque, ${ }^{68}$ increased expression of chemotactic factors, ${ }^{69}$ and increased expression of MMP $1,{ }^{70}$ which have recently led to the possibility of CRP of being a proinflammatory factor in atherosclerosis and its progression. It thus seems that CRP too, in many ways participates in the web formed by the many cytokines in the process of atherosclerosis. Figure 1 shows the pathways by which the cytokines and CRP act to increase atherogenesis.

\section{ROLE OF ANTIGENS AND IMMUNE RESPONSE IN ATHEROSCLEROSIS}

Evidences for activation of both the innate and the adaptive immune systems in atherosclerosis have lead to the search for the possible antigens involved in the initiation of these responses. Multiple antigens have been studied and proposed as the culprits, including oxLDL, heat shock proteins (HSP), and exogenous pathogens. oxLDL is a modified form of lipoprotein that has been seen to be present in both animals and humans. ${ }^{71}$ Studies have shown evidence regarding oxLDL as being an important antigen in the immune response in atherosclerosis. ${ }^{72}{ }^{73}$ Further evidence showed that oxLDL can have an important role in cellular immune responses in atherosclerosis driving the activation of IFN gamma secreting Thl cells ${ }^{74}$ and that it might play a part in antigen driven $\mathrm{T}$ cell response leading to plaque instability. ${ }^{75}$ One other possible autoantigen having a role in atherosclerosis is the HSP. These are proteins produced in large amounts by injured cells and act to limit denaturation of other cellular proteins. These proteins also act to start the autoimmune processes in many inflammatory disorders. In animal models HSP-65 has been seen to have a role in the process of atherosclerosis. ${ }^{76} 77$ It is possible that these proteins have a role in innate immunity via activation of TLR4. ${ }^{78}$ Studies in human subjects show a possible role of HSP in early atherosclerotic disease. ${ }^{79}$ The presence of HSP60 antibodies was further seen to be associated with disease severity in CAD. ${ }^{80}$ Several studies have given evidence that show a link between atherosclerosis and the presence of some pathogens. One such pathogen, Chlamydia pneumoniae, has been detected in atherosclerotic lesions ${ }^{81} 82$ and that the presence of this pathogen can lead to the activation of $\mathrm{T}$ cells within the atherosclerotic lesions. ${ }^{83}$ There are certain groups of viruses that have been postulated to play a part in atherosclerosis. Among them the herpes simplex virus and cytomegalovirus have been found in the atherosclerotic lesions. ${ }^{84} 85$ Further studies are needed to establish the direct cause-effect relation between atherosclerosis and the pathogens.

\section{CLINICAL SIGNIFICANCE \\ Cytokines as inflammatory markers}

With increasing evidence for the role of inflammation in atherosclerosis and its progression to the clinical syndromes, clinicians are looking towards possible biomarkers for risk stratification of the atherosclerotic CADs. Multiple cytokines and acute phase reactants have been studied having possible parts to predict cardiovascular events in healthy men as well 
as for risk stratification in established cases of CAD. Most widely studied is the acute phase reactant, CRP. Studies have shown the significance of CRP in risk prediction for cardiovascular events in healthy people (6) $^{87}$ and also in established CAD. ${ }^{88} 89$ The secondary proinflammatory cytokine, IL6, is another such marker that has been seen to be of value in prediction of adverse events in patients with established CAD..$^{90}$ With the Th cells having a central regulatory role in the immune processes and thus also in the inflammatory response in atherosclerosis, the cytokines related to the functioning of these cells can become possible candidate biomarkers. The concentration of IL10, a Th2 cytokine having anti-inflammatory properties, has been seen to be decreased in the acute coronary syndromes than that in stable CAD. Furthermore, lower concentration of IL10 in unstable $\mathrm{CAD}$ was associated with increased risk for cardiovascular events. ${ }^{92}$ One cytokine recently described as an important proatherogenic factor is seen to be a potential candidate biomarker for risk prediction in CAD is IL18. Blankenberg et al showed its value in prediction of cardiovascular events in healthy people ${ }^{93}$ and in established CAD. ${ }^{94}$ With continued introduction of new drugs and the availability of a range of therapeutic modalities for ischaemic heart diseases, we believe a more refined approach to risk stratification would help the clinician to choose the appropriate therapeutic strategy. These inflammatory markers thus deserve further studies to confirm their role in the risk stratification of CAD.

\section{Therapeutic implications}

With increasing evidence for the significant role of inflammation and the cytokines involved together with the Th1/Th2 imbalance in atherosclerosis and its progression to CADs, the cytokines can become potential therapeutic targets. IL10 has been tried in experimental models and has been seen to have a protective role against atherosclerosis. ${ }^{27}$ Furthermore, IL10 gene transfer in apolipoprotein E- knockout mice resulted in a reduction in atherosclerotic area and macrophage infiltrated area, and a decrease in plasma IFN gamma level. ${ }^{95}$ Inhibition of atherogenesis in murine models has been achieved with interleukin binding protein ILl8bp, thus suggesting that inhibition of IL18 can lead to increased plaque stability. ${ }^{96}$ Direct blocking of IFN gamma functioning by targeted disruption of the IFN gamma receptors led to an inhibition of atherosclerosis by $60 \%$ in apoE-knockout mice. ${ }^{97}$ It has further been seen that induction of a regulatory $\mathrm{T}$ cell type $1(\operatorname{Tr} l)$ response that inhibits Thl responses by inducing a bystander immune suppression limited the development of atherosclerosis in apolipoprotein E-knockout mice. ${ }^{98}$ Despite the strong potential of the cytokines maintaining the Th cell balance as a therapeutic target in atherosclerosis, it must not be forgotten that they also have wide ranging functions within the immune system in general. As an example, IL2, IL12, and IL18 involved mainly with the Thl response have been implicated as potent antitumour agents and their inhibition may increase the risk of neoplasia. The Th2 cytokines on the other hand have a role in the pathogenesis of autoimmune diseases and prolonged up-regulation of the Th2 cytokines might lead to the development of a variety of autoimmune disorders. Difficulties in therapeutic interventions targeting the various cytokines involved are thus attributable to the pleiotropic effects of the cytokines in the immune system as a whole. The aim thus if any regarding the therapeutic intervention should be short term one or a localised use at the atherosclerotic lesion.

\section{CONCLUSION}

With recent developments in the field of immunology, there has been a great progress in the study of Th cell differentiation. Furthermore, with increasing evidence regarding the role of inflammation in atherosclerosis and further progression to $\mathrm{CAD}$, the cytokines surrounding the Th cells have been seen to play an important part in orchestrating the inflammatory response. An increase in the proinflammatory cytokine series and a compromise in the production of antiinflammatory cytokines give evidence for the shift in the Th1/Th2 balance with increased role for Th1 dominance in atherosclerosis as well as the acute coronary syndromes. Among the Thl cytokines themselves, IFN gamma seems to lie at the epicentre sharing a cause-effect relation with the progression of atherosclerosis. Further studies need to be conducted to confirm the causal relation between the various cytokines surrounding the Th cells and the occurrence of ACS together with the severity of the disease process, and to develop the related cytokines as inflammatory markers and therapeutic targets.

\section{Authors' affiliations}

S G Baidya, Institute of Cardiovascular Diseases, Union Hospital, Tongii Medical College, Huazhong University Of Science and Technology,

Wuhan, Hubei Province, PR China; sajangopal@hotmail.com

Q-T Zeng, Department of Interventional Cardiology, Institute of

Cardiovascular Diseases, Union Hospital, Tongji Medical College,

Huazhong University Of Science and Technology

Funding: none.

Conflicts of interest: none.

\section{REFERENCES}

1 Napoli C, Glass CK, Witztum JL, et al. Influence of maternal hypercholesterolemia during pregnancy on progression of early atherosclerotic lesions in childhood: fate of early lesions in children (FELIC) study. Lancet 1999;354:1234-41.

2 Stary HC, Chandler AB, Glagov S, et al. A definition of initial, fatty streak, and intermediate lesions of atherosclerosis: a report from the Committee on Vascular Lesions of the council on atherosclerosis, American Heart Association. Circulation 1994;89:2462-78.

3 Stemme S, Holm J, Hansson GK. T lymphocytes in human atherosclerotic plaques are memory cells expressing CD45RO and the integrin VLA-1. Arteriosd Thromb 1992;12:206-11.

4 Zhou X, Stemme S, Hansson GK. Evidence for a local immune response in atherosclerosis: CD4+ T cells infiltrate lesions of apo E-deficient mice. Am J Pathol 1996; 149:359-66.

5 Frostegård J, Ulfgren AK, Nyberg P, et al. Cytokine expression in advanced human atherosclerotic plaques: dominance of pro-inflammatory (Th1) and macrophage-stimulating cytokines. Atherosclerosis 1999; 145:33-43

6 Abbas AK, Murphy KM, Sher A. Functional diversity of helper T lymphocytes. Nature 1996;383:787-93.

7 Pulendran B, Smith JL, Caspary G, et al. Distinct dendritic cell subsets differentially regulate the class of immune response in vivo. Proc Natl Acad Sci U S A 1999;96:1036-41.

8 Mills CD, Kincaid K, Alt JM, et al. M-1/M-2 macrophages and the Th1/Th2 paradigm. J Immunol 2000; 164:6166-73.

9 Rock FL, Hardiman G, Timans JC, et al. A family of human receptors structurally related to Drosophila Toll. Proc Natl Acad Sci U S A 1998;95:588-93.

10 Barton GM, Medzhitov R. Control of adaptive immune responses by toll-like receptors. Curr Opin Immunol 2002;14:380-3.

11 Brand K, Page S, Rogler G, et al. Activated transcription factor nuclear factorkappa $B$ is present in the atherosclerotic lesion. J Clin Invest 1996;97:1715-22

12 Michelsen KS, Wong MH, Shah PK, et al. Lack of toll-like receptor 4 or myeloid differentiation factor 88 reduces atherosclerosis and alters plaque phenotype in mice deficient in apolipoprotein E. Proc Natl Acad Sci U S A 2004;101:10679-84.

13 Kanters E, Pasparakis M, Gijbels MJ, et al. Inhibition of NF-kappaB activation in macrophages increases atherosclerosis in LDL receptor-deficient mice. J Clin Invest 2003; 1 12:1 176-85.

14 Kurt-Jones EA, Hamberg S, Ohara J, et al. Heterogeneity of helper/inducer T lymphocytes. I. Lymphokine production and lymphokine responsiveness. J Exp Med 1987; 166:1774-87.

15 Upadhya S, Mooteri S, Peckham N, et al. Atherogenic effect of interleukin-2 and antiatherogenic effect of interleukin-2 antibody in apo-E-deficient mice. Angiology 2004;55:289-94.

16 Mazzone A, De Servi S, Vezzoli M, et al. Plasma levels of interleukin 2, 6, 10 and phenotypic characterization of circulating $T$ lymphocytes in ischemic heart disease. Atherosclerosis 1999;145:369-74. 
17 Khew-Goodall Y, Wadham C, Stein BN, et al. Stat6 activation is essential for interleukin-4 induction of P-selectin transcription in human umbilical vein endothelial cells. Arterioscler Thromb Vasc Biol 1999; 19:1421-9.

18 Lee YW, Kuhn H, Kaiser S, et al. Interleukin 4 induces transcription of the 15lipoxygenase I gene in human endothelial cells. J Lipid Res 2001b;42:783-91.

19 Barks JL, McQuillan JJ, lademarco MF. TNF-alpha and IL-4 synergistically increase vascular cell adhesion molecule-1 expression in cultured vascular smooth muscle cells. J Immunol 1997; 159:4532-8.

20 Vadiveloo PK, Stanton HR, Cochran FW, et al. Interleukin-4 inhibits human smooth muscle cell proliferation. Artery 1994;21:161-81.

21 Elliott MJ, Gamble JR, Park LS, et al. Inhibition of human monocyte adhesion by interleukin-4. Blood 1991;77:2739-45.

22 Uyemura K, Demer LL, Castle SC, et al. Cross-regulatory roles of IL-12 and IL10 in atherosclerosis. J Clin Invest 1996;97:2130-8.

23 Fiorentino DF, Bond MW, Mosmann TR. Two types of mouse T helper cell. IV. Th2 clones secrete a factor that inhibits cytokine production by Th1 clones. J Exp Med 1989; 170:2081-95.

24 Del Prete G, De Carli M, Almerigogna F, et al. Human IL-10 is produced by both type 1 helper (Th1) and type 2 helper (Th2) T cell clones and inhibits their antigen-specific proliferation and cytokine production. J Immunol 1993;150:353-60.

25 de Waal Malefyt R, Abrams RJ, Bennett B, et al. Interleukin-10 (IL-10) inhibits cytokine synthesis by human monocytes - an autoregulatory role of IL-10 produced by monocytes. J Exp Med 1991;174:1209-20.

26 Pinderski Oslund L, Hedrick CC, Olvera T, et al. Interleukin-10 blocks atherosclerotic events in vitro and in vivo. Arterioscler Thromb Vasc Biol 1999; 19:2847.

27 Mallat Z, Besnard S, Duriez $M$, et al. Protective role of interleukin-10 in atherosclerosis. Circ Res 1999;85:e17-24.

28 Smith DA, Irving SD, Sheldon J, et al. Serum levels of the antiinflammatory cytokine interleukin-10 are decreased in patients with unstable angina. Circulation 2001;104:746-9.

29 Yamashita H, Shimada K, Seki E, et al. Concentrations of interleukins, interferon, and $C$-reactive protein in stable and unstable angina pectoris. Am J Cardiol 2003;91:133-6.

30 Lee TS, Yen HC, Pan CC, et al. The role of interleukin 12 in the development of atherosclerosis in ApoE-deficient mice. Arterioscler Thromb Vasc Biol 1999; 19:734-42.

31 Yoshimoto T, Takeda K, Tanaka T, et al. IL-12 up-regulates IL-18 receptor expression on T cells, Th1 cells, and B cells: synergism with IL-18 for IFNgamma production. J Immunol 1998;161:3400-7.

32 Nakahira M, Ahn HJ, Park WR, et al. Synergy of IL-12 and IL-18 for IFNgamma gene expression: IL-12-induced STAT4 contributes to IFN-gamma promoter activation by up-regulating the binding activity of IL-18-induced activator protein 1. J Immunol 2002;168:1146-53.

33 Okamura $\mathrm{H}$, Tsutsi $\mathrm{H}$, Komatsu $\mathrm{T}$, et al. Cloning of a new cytokine that induces IFN-gamma production by T cells. Nature 1995;378:88-91

34 Micallef MJ, Ohtsuki T, Kohno K, et al. Interferon-gamma-inducing facto enhances $T$ helper 1 cytokine production by stimulated human $T$ cells: synergism with interleukin-12 for interferon-gamma production. Eur J Immunol 1996;26:1647-51

35 Gerdes N, Sukhova GK, Libby P, et al. Expression of interleukin (IL)-18 and functional IL-18 receptor on human vascular endothelial cells, smooth muscle cells, and macrophages: implications for atherogenesis. J Exp Med 2002; 195:245-57.

36 Mallat Z, Corbaz A, Scoazec A, et al. Expression of interleukin-18 in human atherosclerotic plaques and relation to plaque instability. Circulation $2001 ; 104: 1598-603$.

37 Whitman SC, Ravisankar P, Daugherty A. Interleukin-18 enhances atherosclerosis in apolipoprotein $\mathrm{E}(-/-)$ mice through release of interferongamma. Circ Res 2002;90:E34-8.

38 Mallat Z, Henry P, Fressonnet R, et al. Increased plasma concentrations of interleukin-18 in acute coronary syndromes. Heart 2002;88:467-9.

39 Huber SA, Sakkinen P, David C, et al. T-helper-cell phenotype regulates atherosclerosis in mice under conditions of mild hypercholesterolemia. Circulation 2001;103:2610-16.

40 Laurat E, Poirier B, Tupin E, et al. In vivo down-regulation of T helper cell 1 immune responses reduces atherogenesis in apolipoprotein E-knockout mice. Circulation 2001; 104:197-202.

41 Fernandez-Botran R, Sanders VM, Mosmann TR, et al. Lymphokine-mediated regulation of the proliferative response of clones of T helper 1 and T helper 2 cells. J Exp Med 1988;168:543-58.

42 Hansson GK, Jonasson L, Holm J, et al. yinterferon regulates vascular smooth muscle proliferation and la expression in vivo and in vitro. Circ Res 1988:63:712-19

43 Li H, Cybulsky MI, Gimbrone MA, et al. An atherogenic diet rapidly induces VCAM-I, a cytokine-regulatable mononuclear leukocyte adhesion molecule, in rabbit aortic endothelium. Arterioscler Thromb 1993;13:197-204.

44 Jonasson L, Holm J, Skalli O, et al. Expression of class II transplantation antigen on vascular smooth muscle cells in human atherosclerosis. J Clin Invest 1985;76:125-31.

45 Boehm U, Klamp T, Groot $M$, et al. Cellular responses to interferon- $\gamma$. Annu Rev Immunol 1997:15:749-95.

46 Jonasson L, Hansson GK, Bondjers G, et al. Interferon-gamma inhibits lipoprotein lipase in human monocyte-derived macrophages. Biochim Biophys Acta 1990; 1053:43-8.

47 Reiss AB, Awadallah NW, Malhotra S, et al. Immune complexes and IFN- $\gamma$ decrease cholesterol 27-hydroxylase in human arterial endothelium and macrophages J Lipid Res 2001;42:1913-22.
48 Panousis CG, Zuckerman SH. Interferon-gamma induces downregulation of Tangier disease gene (ATP-binding-cassette transporter 1) in macrophagederived foam cells. Arterioscler Thromb Vasc Biol 2000;20:1565-71.

49 Panousis CG, Zuckerman SH. Regulation of cholesterol distribution in macrophage-derived foam cells by interferon-gamma. J Lipid Res 2000;41:75-83.

50 Wuttge DM, Zhou X, Sheikine Y, et al. CXCL16/SRPSOX is an interferongamma-regulated chemokine and scavenger receptor expressed in atherosclerotic lesions. Arterioscler Thromb Vasc Biol 2004;24:750-5.

51 Wagsater D, Olofsson $P$, Norgren L, et al. The chemokine and scavenger receptor CXCL16/SR-PSOX is expressed in human vascular smooth muscle cells and is induced by interferon-gamma. Biochem Biophys Res Commun 2004:325: 1187-93.

52 Minami M, Kume N, Shimaoka T, et al. Expression of SR-PSOX, a novel cellsurface scavenger receptor for phosphatidylserine and oxidized LDL in human atherosclerotic lesions Arterioscler Thromb Vasc Biol 2001;21:1796-800.

53 Whitman SC, Ravisankar P, Elam H, et al. Exogenous interferon- $\gamma$ enhances atherosclerosis in apolipoprotein E-/- mice. Am J Pathol 2000;157:1819-24.

54 Naghavi $M$, Libby $P$, Falk E, et al. From vulnerable plaque to vulnerable patient: a call for new definitions and risk assessment strategies: part I. Circulation 2003;108:1664-72.

55 Sempowski GD, Derdak S, Phipps RP. Interleukin-4 and interferon-gamma discordantly regulate collagen biosynthesis by functionally distinct lung fibroblast subsets. J Cell Physiol 1996;167:290-6.

56 Sukhova GK, Shi G-P, Simon DI, et al. Expression of elastolytic cathepsins S and $\mathrm{K}$ in human atheroma and regulation of their production in smooth muscle cells. J Clin Invest 1998; 102:576-83.

57 Xie QW, Kashiwabara Y, Nathan C. Role of transcription factor NF-kappa B/ Rel in induction of nitric oxide synthase. J Biol Chem 1994;269:4705-8.

58 Biörkerud S, Biörkerud B. Apoptosis is abundant in human atherosclerotic lesions, especially in inflammatory cells (macrophages and T cells), and may contribute to the accumulation of gruel and plaque instability. Am J Pathol 1996; 149:367-80.

59 Inagaki Y, Yamagishi S, Amano S, et al. Interferon-gamma induced apoptosis and activation of THP-1 macrophages. Life Sci 2002;71:2499-508.

60 Branen L, Hovgaard L, Nitulescu M, et al. Inhibition of tumor necrosis factoralpha reduces atherosclerosis in apolipoprotein $\mathrm{E}$ knockout mice. Arterioscler Thromb Vasc Biol 2004;24:2137-42.

61 Tipping PG, Hancock WW. Production of tumor necrosis factor and interleukin-1 by macrophages from human atheromatous plaques. Am J Pathol $1991 ; 138: 951-60$.

62 Dinarello CA. Biological basis for Interleukin-1 in disease. Blood 1996:87:2095-47.

63 Loppnow H, Libby P. Proliferating or interleukin 1-activated human vascular smooth muscle cells secrete copious interleukin 6. J Clin Invest 1990;85:731-8

64 Lotz M. Interleukin-6. Cancer Invest 1993;11:732-42.

65 Ikeda U, Ikeda M, Seino Y, et al. Interleukin 6 gene transcripts are expressed in atherosclerotic lesions of genetically hyperlipidemic rabbits. Atherosclerosis 1992;92:213-18.

66 Castell JV, Andus T, Kunz D, et al. Interleukin-6: the major regulator of acutephase protein synthesis in man and rat. Ann N Y Acad Sci 1989;557:87-101

67 Yasojima K, Schwab C, McGeer EG, et al. Generation of C-reactive protein and complement components in atherosclerotic plaques. Am J Pathol $2001 ; 158: 1039-51$

68 Jialal I, Devaraj S, Venugopal SK. C-reactive protein: risk marker or mediator in atherothrombosis? Hypertension 2004;44:1-6.

69 Han KH, Hong K, Park J, et al. C-reactive protein promotes monocyte chemoattractant protein-1-mediated chemotaxis through upregulating CC chemokine receptor 2 expression in human monocytes. Circulation 2004; 109:2566-71.

70 Williams TN, Zhang CX, Game BA, et al. C-reactive protein stimulates MMP-1 expression in U937 histiocytes through $\mathrm{Fc}$ [gamma]RIl and extracellular signalregulated kinase pathway: an implication of CRP involvement in plaque destabilization. Arterioscler Thromb Vasc Biol 2004;24:61-6.

71 Witztum JL, Steinberg D. The oxidative modification hypothesis of atherosclerosis: Does it hold for humans? Trends Cardiovasc Med $2001 ; 11: 93-102$.

72 Palinski W, Rosenfeld ME, Ylä-Herttuala S, et al. Low density lipoprotein undergoes oxidative modification in vivo. Proc Natl Acad Sci U S A 1989:86:1372-6.

73 Salonen JT, Ylä-Herttuala S, Yamamoto R, et al. Autoantibody against oxidised LDL and progression of carotid atherosclerosis. Lancet 1992;339:883-7.

74 Stemme S, Faber B, Holm J, et al. T lymphocytes from human atherosclerotic plaques recognize oxidized LDL. Proc Natl Acad Sci U S A 1995;92:3893-7.

75 Caligiuri G, Paulsson G, Nicoletti A, et al. Evidence for antigen-driven T-cell response in unstable angina. Circulation 2000;102:1114-19.

$76 \mathrm{Xu} \mathbf{Q}$, Dietrich $\mathrm{H}$, Steiner $\mathrm{HJ}$, et al. Induction of arteriosclerosis in normocholesterolemic rabbits by immunization with heat shock protein 65 . Arterioscler Thromb 1992; 12:789-99.

77 George J, Shoenfeld Y, Afek A, et al. Enhanced fatty streak formation in C57BL/6J mice by immunization with heat shock protein-65. Arterioscler Thromb Vasc Bio 1999:19:505-10.

78 Vabulas RM, Ahmad-Nejad P, da Costa C, et al. Endocytosed HSP60s use toll-like receptor 2 (TLR2) and TLR4 to activate the toll/interleukin-1 receptor signaling pathway in innate immune cells. J Biol Chem 2001;276:31332-9.

79 Pockley AG, Wu R, Lemne C, et al. Circulating heat shock protein 60 is associated with early cardiovascular disease. Hypertension 2000;36:303-7. 
80 Zhu J, Quyyumi AA, Rott D, et al. Antibodies to human heat-shock protein 60 are associated with the presence and severity of coronary artery disease: evidence for an autoimmune component of atherogenesis. Circulation 2001;103:1071-5.

81 Kuo CC, Gown AM, Benditt EP, et al. Detection of Chlamydia pneumoniae in aortic lesions of atherosclerosis by immunocytochemical stain. Arterioscler Thromb 1993; 13:1501-4.

82 Muhlestein JB, Hammond EH, Carlquist JF, et al. Increased incidence of Chlamydia species within the coronary arteries of patients with symptomatic atherosclerotic versus other forms of cardiovascular disease. J Am Coll Cardiol 1996;27:1555-61.

83 Gaston JS, Curry AJ, Portig I, et al. Immune responses to Chlamydia antigens in atherosclerosis. Herz 2000;25:73-8.

84 Hendrix MGR, Salimans MMM, Boven CPA, et al. High prevalence of latently present cytomegalovirus in arterial walls of patients suffering from grade III atherosclerosis. Am J Pathol 1990;136:23-8.

85 Ibrahim Al, Obeid MT, Jouma MJ, et al. Detection of herpes simplex virus, cytomegalovirus and Epstein-Barr virus DNA in atherosclerotic plaques and in unaffected bypass grafts. J Clin Virol 2005:32:29-32.

86 Koenig W, Sund M, Frohlich M, et al. C-reactive protein, a sensitive marker of inflammation, predicts future risk of coronary heart disease in initially healthy middle-aged men: results from the MONICA (monitoring trends and determinants in cardiovascular disease) Augsburg cohort study, 1984 to 1992. Circulation 1999;99:237-42.

87 Ridker PM, Buring JE, Shih J, et al. Prospective study of C-reactive protein and the risk of future cardiovascular events among apparently healthy women. Circulation 1998;98:731-3.

88 Morrow DA, Rifai N, Antman EM, et al. C-reactive protein is a potent predictor of mortality independently of and in combination with troponin $\mathrm{T}$ in acute coronary syndromes: a TIMI 11A substudy. Thrombolysis in myocardial infarction. J Am Coll Cardiol 1998;31:1460-5.

89 Heeschen C, Hamm CW, Bruemmer J, et al. Predictive value of C-reactive protein and troponin $\mathrm{T}$ in patients with unstable angina: a comparative analysis. CAPTURE Investigators. Chimeric C7E3 antiplatelet therapy in unstable angina refractory to standard treatment trial. J Am Coll Cardiol 2000;35: 1535-42.

90 Biasucci LM, Liuzzo G, Fantuzzi G, et al. Increasing levels of interleukin (IL)1 Ra and IL- 6 during the first 2 days of hospitalization in unstable angina are associated with increased risk of in-hospital coronary events. Circulation 1999;99:2079-84.

91 Passoni F, Morelli B, Seveso G, et al. Comparative short-term prognostic value of hemostatic and inflammatory markers in patients with non-ST elevation acute coronary syndromes. Ital Heart J 2002;3:28-33.

92 Anguera I, Miranda-Guardiola F, Bosch X, et al. Elevation of serum levels of the anti-inflammatory cytokine interleukin-10 and decreased risk of coronary events in patients with unstable angina. Am Heart $J$ 2002;144:811-17.

93 Blankenberg S, Luc G, Ducimetiere P, et al. PRIME Study Group. Interleukin 18 and the risk of coronary heart disease in European men: the prospective epidemiological study of myocardial infarction (PRIME). Circulation 2003; 108:2453-9.

94 Blankenberg S, Tiret L, Bickel C, et al. AtheroGene Investigators. Interleukin18 is a strong predictor of cardiovascular death in stable and unstable angina. Circulation 2002; 106:24-30.

95 Namiki M, Kawashima S, Yamashita T, et al. Intramuscular gene transfer of interleukin-10 cDNA reduces atherosclerosis in apolipoprotein E-knockout mice. Atherosclerosis 2004;172:21-9.

96 Mallat Z, Corbaz A, Scoazec A, et al. Interleukin-18/interleukin-18 binding protein signaling modulates atherosclerotic lesion development and stability. Circ Res 2001;89:E41-5.

97 Gupta S, Pablo AM, Jiang XC, et al. IFN- $\gamma$ potentiates atherosclerosis in apoE knock-out mice. J Clin Invest 1997;99:2752-61.

98 Mallat Z, Gojova A, Brun V, et al. Induction of a regulatory T cell type 1 response reduces the development of atherosclerosis in apolipoprotein $\mathrm{E}$ knockout mice. Circulation 2003;108:1232-7. 